researcher at the Federal University of Itajubá.

Meanwhile, the government has tried to stimulate the economy with tax breaks on the sale of new cars. That, combined with the cost of pure ethanol, has meant that "the share of alcohol in our transport fuel matrix has dropped from 55\% in 2008 to 35\%", says André Ferreira, head of the Institute for Energy and the Environment, a think-tank in São Paulo.

According to Antônio de Pádua Rodrigues, technical director and acting president of UNICA, Brazil's sugar-cane industry association, the government knows that the situation is unsustainable. It has promised the industry that petrol prices will go up next year, and that the blend of ethanol will rise from $20 \%$ to $25 \%$, the maximum allowed by law. But it will take time for the industry to bounce back from its poor fortune, and ethanol is likely to remain scarce and expensive for the next two years, say Rodrigues and Horta.

Now, Brazil hopes to tap into a new biofuel source: second-generation ethanol, produced from the tough cellulose in plant stalks. Cellulose is difficult to break down and ferment, but several facilities in the United States are on

$\rightarrow$ NATURE.COM

Read more in

Nature's chemistry and energy Outlook. go.nature.com/q6zodw the verge of making commercial cellulosic ethanol — for example, by using specialist enzymes to break down the longchain cellulose molecules
— and Brazil doesn't want to be left behind.

In December last year, the Brazilian Development Bank launched a 1-billion-real (US\$481-million) credit line to stimulate research and development in cellulosic biofuels and other advanced sugar-cane technologies. The Center for Sugarcane Technology, an industry-sponsored organization based in São Paulo, has taken up a 357-million-real loan to build a cellulosic ethanol plant next year, which would use waste plant matter from conventional sugar-cane fermentation. "We can double fuel yield per hectare when the technology is mature", says Oswaldo Godoy, a project manager at the organization.

The Brazilian Agricultural Research Company (EMBRAPA) is also throwing its weight behind bioenergy. Its president, Maurício Lopes, a geneticist who took office in October, has promised to build up research on biomass technology and double EMBRAPA's funding for that area, which today stands at a modest 24 million real per year. "I want to believe that the current state of the ethanol sector is a temporary blip," he says. Lopes says that Brazil will be "unbeatable" once cellulosic technology matures. "No other country has the logistics we have in place, or the number of different species we can derive ethanol from."

But cellulosic ethanol won't be a quick fix, says Horta. "Nothing shall compete with conventional sugar-cane ethanol until 2050."
FUELLING BRAZIL'S TRANSPORT BOOM

More vehicles and falling ethanol production is prompting a switch to petrol blends.
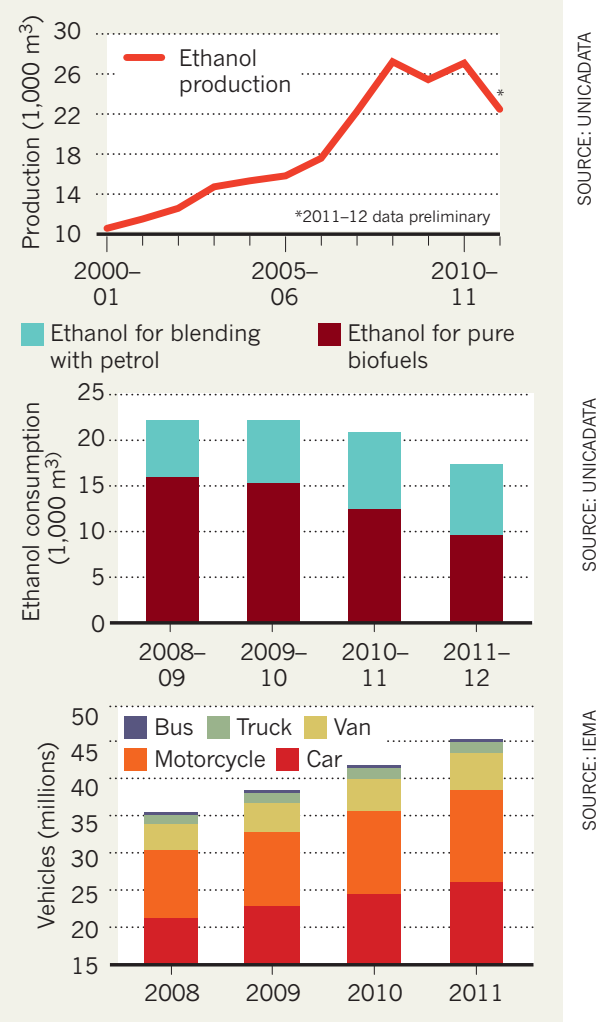

\title{
Daily dose of toxics to be tracked
}

\section{Exposome studies will tie environmental exposure to biological triggers of disease.}

\section{BY EWEN CALLAWAY}

1 Think of it as a benevolent Big Brother. European researchers are gearing up to monitor thousands of people by giving them smartphones to record the chemicals to which they are exposed every day.

Two projects this week announced that they had won a combined $€ 17.3$ million (US\$22.4 million) from the European Commission to study the 'exposome' - the effects of environmental exposures on health. The researchers hope that the four-year studies will benefit public health in ways that genome research so far has not.

Genome-wide association studies, in which scientists search for genetic variants linked to disease, have failed to fully explain why some people are more susceptible than others to chronic diseases, such as type 2 diabetes. "There's been too much emphasis on genetic factors, which contribute relatively little to disease compared with environmental factors," says Martyn Smith, a toxicologist at the University of California, Berkeley, who is participating in the newly funded Exposomics project. Paolo Vineis, an environmental epidemiologist at Imperial College London, leads the $€ 8.7$-million project.

Subjects will carry smartphones equipped with sensors to measure exposures, and their blood will be analysed to monitor molecular changes. Most participants are already involved in other long-term health studies. One goal is to look for biomarker differences between people walking through areas with low air pollution and those exposed to urban fumes, in order to understand the triggers for conditions such as heart disease, asthma and lung cancer.

Vineis's exposomics approach has already uncovered gene-expression signatures that link people's leukaemia risk with their exposure to heavy metals and other toxic chemicals, for example.

The second project, the $€ 8.6$-million Human Early-Life Exposome, will focus on children and pregnant women. Children are more susceptible to environmental influences because their bodies are smaller and their organs are still developing, says epidemiologist Martine Vrijheid at the Centre for Research in Environmental Epidemiology in Barcelona, Spain, who heads the project. The researchers will track disease biomarkers to assess the effects of environmental exposures on growth, obesity, immune development and asthma. Both projects will generate vast amounts of data, and Vineis and Vrijheid are developing data-sharing policies to enable other researchers to mine the resource.

Interest in exposomics is also growing in the United States. This year, the US National Research Council called for greater investment in exposome research, and the National Institute for Environmental Health Sciences plans to make it a priority, although it has yet to invest in any projects as large as the European efforts, says the institute's David Balshaw. "We see this as a major priority," he says. 